\title{
Tourism Dynamics and Sustainability: A Compared Analysis in Mediterranean Islands. Evidence for Post-Covid-19 Strategies
}

\author{
Giovanni Ruggieri ${ }^{1 *}$ and Patrizia Calò ${ }^{2}$ \\ 1 University of Palermo, Department of Economics, Business and Statistics; giovanni.ruggieri@unipa.it \\ 2 Observatory on Tourism in the European Islands - OTIE; research@otie.org \\ * Correspondence: giovanni.ruggieri@unipa.it
}

\begin{abstract}
Tourism may not sustainably support territories with limited natural resource stock as islands. The volume in visitor arrivals and the industry investments can increase the pressure even beyond sustainable levels. There is an evident and unresolved tension between these two great polarities, sustainability and economic growth driven by tourism. The aim for policymakers is to find an acceptable equilibrium between these two dimensions. This paper investigates tourism evolution between 2007 and 2019 in 15 Mediterranean islands, comparing tourism pressures through statistical indicators. The analysis will compare tourism demand and supply trends in these contexts. The performances will be evaluated to identify the Islands positioning between sustainability needs and tourism development opportunities while considering post-covid-19 challenges.
\end{abstract}

Keywords: tourism, islands, impact, economic development, sustainability

\section{Introduction}

The consideration of tourism as a development driver is still under discussion because the efforts to enhance local benefits and competitiveness in tourism seem controversial from a sustainable perspective. Despite this consideration, the potential economic growth of tourism is documented in international literature, as highlighted in several recent studies. In general, when tourist activity grows, visitors increase and spend more money in a destination, leading to an increase in the GDP and economic growth [1-11].

With regard to insular contexts, the need to consider the peculiarity of these territories emerges. Tourism in islands is not a solved question because islands have a limited natural resource stock, so the increase in visitor arrivals can put pressure on the use of these to their viability limit, even beyond sustainable levels. Studies on the impact of tourism on island destinations worldwide have shown both positive and negative externalities generated by tourism in these contexts $[12,13]$. The increase of tourism flows could have unexpected detrimental impacts on environments and local communities, deriving from the excess of tourism, called overtourism[14, 15, 16]. Monitoring tourism impacts is fundamental to avoid negative effects on environment and residents [17], and finding new opportunities for the local industry's expansion [18, 19, 20, 21]. In terms of sustainability [2222] (1-20), for coastal or island areas is not easy being the territorial target for significant tourism flows. In this way, Mediterranean islands' environmental and cultural images can act as magnets attracting many tourists (i.e. overnight visitors). But, the arrival of consistent tourist flows could alter the fragile insular ecological equilibrium, negatively affecting those natural and cultural resources that have initially aroused tourists' interest in the knowledge of that place and ultimately could cause the displacement of tourists to the islands. That's the "paradox of tourism in the islands" [23] (131-143), and this is even more significant in the Mediterranean space. Tourism appears as an essential part of the local economy [13], being perceived generally as one of the few economic development opportunities available in the insular context and the only natural economic alternative (at the production level, economic activity, and income) capable of responding to the socio- 
economic needs of its inhabitants. Given that, the need to contain and eliminate negative effects on the environment and residents emerges.

The unresolved tension between these two great polarities, sustainability, and economic growth, is still far from an acceptable equilibrium. In this sense, a current of critical thinking $[2424,2525]$ rejects the use of the term "sustainable tourism," suggesting that its use can be instrumented by political actors whose fundamental objective is somehow "green" which is simply economic growth. Adequate implementation of sustainable tourism [26] must emphasize the systematic management of environmental degradation, the generation of economic benefits for the receiving communities, and residents' perception 27, 2828].

This paper will explain how sustainable tourism was an accepted and practical reality in Mediterranean islands and what tourism development could be undertaken in these contexts. A sample of the Mediterranean island territories belonging to the European Union was included in the proposed analysis to explore this possibility.

After examining the features of tourism demand and supply in each insular context, the paper analyses four indicators comparing the results in the different observed islands. The positioning of each context, depending on the combination of the values obtained by the indicators selected in the two years, is observed. This allows us to also consider the evolution over the period observed.

The proposed analysis concerns the performances recorded before the COVID19 pandemic. The effects of COVID 19 on the economy of the Mediterranean islands, especially in terms of tourism, could be defined disastrous, with tourist activity on many islands having been reduced by almost $80 \%$. The combined effect of restrictions (curfews, lockdowns, closing of theatres, discos, the closure of hotels and restaurants) with travel difficulties (border closures, shortage of air and maritime connections, airport closures) and the fear of being infected or becoming infected has caused a tremendous crash of the demand, causing a severe economic crisis worldwide and especially in islands, whose economy depends mainly on tourism. From a sustainability perspective, COVID 19 should be an opportunity to rethink tourism in the Mediterranean islands more consciously, by achieving a balanced equilibrium between the policies to increase tourism industry and public policy to contain and protect the islands territories.

\section{Insularity condition and tourism}

Isolation determines islands' social, cultural, political, and economic life. Historically, being isolated from the outside world, the islands appeared to be considered autarkic societies, without social and economic dynamism and with few commercial relations. Hence this nineteenth-century idea of the islands as ultra-conservative, immovable, and atavistic societies reluctant to change, whose distrustful island population hardly interacts with outsiders. A typical romantic idea but whose influence still continues today [2828].

Separation and unavoidable "territorial discontinuity" affect the life of the islands by questioning their external accessibility, both for those who intend to leave and those who intend to enter the island, since the external mobilization of people can only be carried out through air and maritime transport units. Likewise, uncertainty is generated in essential aspects of island life, such as providing necessities.

Insularity $[30,31]$ requires a port infrastructure adequate to current needs and improved to meet demand expansions. Ports are needed for the reception of vessels, equipped with means for loading, disembarking, and storing goods, with devices for customs control. Passengers' entry and exit must also be foreseen. Likewise, airports and other connected infrastructures are essential for the accessibility to islands and, from the tourist perspective, currently even more important. Itineraries established in island transport may be affected by adverse weather and maritime conditions for navigation or by specific over-demands and thus generate discomfort in the mobilization of ordinary users and consumers. Moreover, critical marine phenomena destroy port facilities, coastal roads, and homes. 
Therefore, insularity can be considered according to two complementary dimensions. The former is related to the physical vulnerability of the islands in spatial terms (isolation, small size or smallness, scarcity of resources) in relation to specific characteristics associated with the physical and geographical features of these contexts. This dimension is persistent in economic-commercial or economic development analysis on the islands. While the latter dimension, the "islandness" [31, 32, presents a rather metaphysical cut, reflects feelings common to all islanders, based on the isolation inherent to the insular, usually in line with solid senses of roots and community.

According to the former dimension, territorial discontinuity increases the costs of external supply products and export goods caused by the mobilization and storage of shipments and landings. In this respect, we talk about the costs of insularity, originating over time a whole literature on the nature of such costs $[33,35,12]$, on the way to measure, calculate and evaluate them $[36,36,37]$ and more recently, how to compensate the excess costs caused by remoteness, insularity, and ultra-peripherality of the island territories $[38,39]$.

We wonder whether it might be more expensive to consume and produce on an island than to do it on the mainland. According to Manera and Garau [28], the natural environment where human activity takes affects and conditions it. For this reason, the costs of insularity are evident since the smaller the territory, the greater the cost of human activity. Moreover, the further the part is from world economic flows, the more the costs increase [28]. From this perspective, the cost of accessing the market is much higher in the case of island economies: if we consider the transport of goods, for example, this is between two and four times more expensive than on the mainland. For this reason, the transfer of raw materials, the higher costs of storing stocks, the degradation of perishable products, and delays due to adverse weather conditions are critical factors which directly affect the competitiveness of island productions [28].

All these factors related to insularity and the verification of their simultaneous presence in these territories have led to the emergence of insular vulnerability [40,41]. In their economic development process [Error! Reference source not found.], the islands start from a situation characterized by a multiplicity of handicaps and physical, financial, and sociocultural weaknesses that cannot be avoided; therefore, a specific policy design is needed. The open debate in the European Union on insularity, its costs, and the way to face them are far from reaching a conclusion.

For island contexts, tourism represents, in this sense, the only policy option to overcome the structural constraints imposed by the small size of their economies and the insular physical conditions.

From an economic point of view, many islands have simply insufficient domestic market demand for a good or service to enable local firms to achieve any efficiencies or economies of scale. However, in the case of tourism, the demand is imported (Incoming Tourism), and thus, the market size can change, and increase, due to the possibility to attract external visitors. In this way, a local firm operating on an island could have a larger market than the local context for its goods and services. Then, they may begin to achieve economies of scale and efficiencies thanks to the tourist flows [43] (453-465). Therefore, islands firms can face the problem of the small size of the local market thanks to the demand deriving from the incoming tourists. Moreover, tourists are high spending people, so the incomes for local enterprises will increase more than proportionally. Given that, insular economies are almost totally based on tourism and related activities.

Another condition which affects islands is the geographical distance, which limits the accessibility to a destination with consequences for tourism flows, which are consequently affected by the higher cost of transport and the difficulty to reach them. Then, also in tourism, the need to consider the costs of insularity in the economic development dynamics arises. 
Island destinations represent a unique cluster, where tourism development and sustainability issues are connected and represent crucial aspects for the local economy and well-being 44]

\section{The survey}

Islands are defined as natural land extensions surrounded by water above the water level at high tide [45] (147-154). This geographic element differentiates them and identifies them from other territorial realities (such as peninsulas, capes, or promontories). Then, both characteristics, isolation and separation, define the island's nature and the basis of its insular condition, i.e., the fact of being an island or "insularity", a defining characteristic of islands, based on isolation and geographic discontinuity. In the selection of the sample observed, we considered the definition of "island" provided by Eurostat [46] as follow:

- $\quad$ Have an area greater than $1 \mathrm{~km} 2$

- $\quad$ Are at least $1 \mathrm{~km}$ away from the mainland

- Do not have bridge connections to the mainland

- Have a stable population of at least 50 people

However, here the two islands of Cyprus and Malta, excluded by the European body since their respective capital cities fall within their territories, are analyzed.

This indicates a first difference between the institutional contexts examined, namely the Mediterranean: island states, autonomous regional islands, and coastal islands, which belong to a region situated on the mainland. Mediterranean islands were classified according to their size and density. The geographical dimension and population are not only featured from a geographical point of view, but they are issues from which tourism impacts cannot be separated.

In this survey a clusterizzation of islands and archipelagos according the 4 following categories was carried out:

1. Micro Islands $=0 \mathrm{Km} 2>$ Island area $<1,000 \mathrm{~km} 2$

2. Small Islands $=1.001 \mathrm{Km} 2>$ Island area $<5.000 \mathrm{Km} 2$

3. Medium Islands $=5.001 \mathrm{Km} 2>$ Island area $<10.000 \mathrm{Km} 2$

4. $\quad$ Large Islands = Island area $>10,001 \mathrm{~km} 2$

The sample of Mediterranean islands (Table 1) was observed in order to analyze the leading type of tourism and sustainability dimensions.

Given this evidence, the need to investigate the performances recorded by islands in the tourism sector arises. Comparing the results obtained with those of other islands could be further relevant to define the best strategies to reach a sustainable development through tourism $[26,47,48]$.

Table 1. Demography and territorial data.

\begin{tabular}{|c|c|c|c|c|}
\hline Islands/Arcipelago & $\begin{array}{l}\text { Island } \\
\text { Group }\end{array}$ & State & Area $\mathrm{Km}^{2}$ & $\begin{array}{c}\text { Population } \\
\text { Density } 2019\end{array}$ \\
\hline Sicily islands & \multirow{2}{*}{ Large } & Italy & 25.703 & 191 \\
\hline Sardinia islands & & Italy & 24.090 & 67 \\
\hline Cyprus & \multirow{3}{*}{ Medium } & Cyprus & 9.251 & 130 \\
\hline Corse & & France & 8.680 & 39 \\
\hline Crete & & Greece & 8.261 & 77 \\
\hline Balearic Islands & \multirow{6}{*}{ Small } & Spain & 4.968 & 239 \\
\hline $\begin{array}{c}\text { North Eastern Aegean } \\
\text { Islands }\end{array}$ & & Greece & 4.260 & 54 \\
\hline Evia & & Greece & 3.662 & 52 \\
\hline Ionian Islands & & Greece & 2.443 & 83 \\
\hline Dodekanisa & & Greece & 2.393 & 80 \\
\hline Cyclades & & Greece & 2.267 & 53 \\
\hline Sporades & \multirow{4}{*}{ Micro } & Greece & 417 & 42 \\
\hline Malta, Gozo and Comino & & Malta & 316 & 1562 \\
\hline Argosaronicos Islands & & Greece & 261 & 227 \\
\hline Tuscan Islands & & Italy & 261 & 131 \\
\hline
\end{tabular}

Source: Observatory on Tourism in the European Islands - OTIE 


\section{Islands evolutionary analysis}

If we consider hotels and other facilities, the Mediterranean islands counted 24.416 (2019) accommodations and 1.813 .269 beds. The distribution of the tourist supply is not uniform in all the islands; one should think that, for example, the Balearic Islands on their own contribute to $25,8 \%$ of the total availability in the Mediterranean islands in terms of beds. The Spanish archipelago is the first, counting more beds than Sardinia and Sicily, although characterised by a territorial extension equal to one-fifth of Sicily, which is the largest Mediterranean island.

The highest proportion of tourist accommodation structures is recorded in Sicily (30,6\%), followed by Sardinia with $23,4 \%$ accommodation establishments.

A further comparison can be made by considering the size of the structures. The hotel accommodation class provides the highest number of beds (1.355.348, in 2019) throughout the Mediterranean, albeit with apparent differences from island to island. The largest hotels are in the Balearic Islands, the Maltese archipelago, the Dodecanese Islands, Sardinia, Crete, Cyprus, and Ionian islands. These contexts have hotels that provide an average of no less than 100 beds, according to a range including the 264 beds in the Balearic Islands and 103 in the Ionian islands.

Table 2. Tourist supply in the European Islands.

\begin{tabular}{|c|c|c|c|c|c|c|c|c|}
\hline \multirow{2}{*}{ Islands } & \multicolumn{2}{|c|}{ Hotels } & \multicolumn{2}{|c|}{ Hotel beds } & \multicolumn{2}{|c|}{$\begin{array}{c}\text { Other } \\
\text { accommodations }\end{array}$} & \multicolumn{2}{|c|}{$\begin{array}{c}\text { Other accommodations } \\
\text { beds }\end{array}$} \\
\hline & 2007 & 2019 & 2007 & 2019 & 2007 & 2019 & 2007 & 2019 \\
\hline Sicily and small islands & 1.192 & 1.328 & 114.583 & 125.780 & 2.562 & 6.145 & 66.828 & 85.143 \\
\hline Sardinia and small islands & 846 & 925 & 97.158 & 110.015 & 1.875 & 4.792 & 92.081 & 107.319 \\
\hline Cyprus & 735 & 814 & 87.804 & 89.200 & 167 & 2 & 4.765 & 988 \\
\hline Corse & 367 & 438 & 21.752 & 25.138 & 250 & 451 & 110.161 & 138.892 \\
\hline Crete & 1.509 & 1.619 & 146.955 & 187.599 & 16 & 15 & 2.815 & 760 \\
\hline Balearic Islands & 1.393 & 1.410 & 326.028 & 371.801 & 1.138 & 1.362 & 108.229 & 95.925 \\
\hline North Eastern Aegean Islands & 403 & 387 & 20.967 & 23.006 & 1 & 1 & 285 & 46 \\
\hline Evia & 225 & 245 & 15.413 & 16.832 & 8 & 10 & 2.180 & 667 \\
\hline Ionian Islands & 897 & 980 & 85.098 & 101.405 & 27 & 24 & 6.549 & 1.866 \\
\hline Dodekanisa & 972 & 1.064 & 120.540 & 167.644 & 3 & 4 & 396 & 152 \\
\hline Cyclades & 942 & 1.090 & 42.316 & 56.037 & 31 & 30 & 8.888 & 2.513 \\
\hline Sporades & 161 & 149 & 10.667 & 10.921 & 0 & 1 & 0 & 72 \\
\hline Malta & 160 & 224 & 39.985 & 46.350 & 6 & 20 & 844 & 1.746 \\
\hline Argosaronicos & 160 & 197 & 7.051 & 8.081 & 0 & 1 & 0 & 60 \\
\hline Tuscan Islands & 210 & 198 & 16.007 & 15.539 & 251 & 490 & 20.869 & 21.772 \\
\hline
\end{tabular}

Source: Observatory on Tourism in the European Islands - OTIE

The other accommodation facilities are smaller than the previous one, except for $\mathrm{Cy}$ prus and Corse, equipped with a small number of large structures with an average size of 494 beds and 308 beds in each establishment. This figure is not surprising since the main kind of other facilities in these contexts is camping. The number of establishments and beds is not enough to explain the actual development of tourism in the Mediterranean islands.

In 2019, the tourism flow which affected the Mediterranean islands totaled 43.819 .664 arrivals, $+53 \%$ than to 2007 , and 215.899 .617 overnight stays, $+34 \%$ compared to 2007. Also, demand flows distribution was not equal in all the contexts examined, as highlighted by the fact that $52 \%$ of arrivals are due to three contexts (Balearic Islands, Sicily, Crete), and $56 \%$ of overnights can be attributed to the Balearic Islands, Crete, and the Dodecanese. In both components of demand, the superiority of the Spanish archipelago arises. Indeed, it represents almost $30 \%$ of arrivals to Mediterranean islands and $32 \%$ of the total overnight stays corresponding to more than 68 million nights. They are left behind all the other contexts with a significant gap. Indeed, if Crete, second in the 
overnight stays, has a hole from the Spanish archipelago of more than 7.000 .000 arrivals, Sicily, which has the second-highest number of admissions, is separated from the first position by more than 50,000,000 nights.

Table 3. Tourist demand variation in the European Islands, 2007 / 2019.

\begin{tabular}{|c|c|c|c|c|c|c|c|c|}
\hline \multirow[b]{2}{*}{ Islands } & \multicolumn{4}{|c|}{ Arrivals } & \multicolumn{4}{|c|}{ Overnights } \\
\hline & 2007 & 2019 & $\begin{array}{l}2019 \\
2007\end{array}$ & Var. $\%$ & 2007 & 2019 & $\begin{array}{l}2019 \\
2007\end{array}$ & Var. \% \\
\hline Sicily & 4.614 .338 & 5.120 .421 & 506.083 & $11 \%$ & 14.602 .145 & 15.114 .931 & 512.786 & $4 \%$ \\
\hline Sardinia & 2.280 .173 & 3.444 .058 & 1.163 .885 & $51 \%$ & 11.851 .213 & 15.145 .885 & 3.294 .672 & $28 \%$ \\
\hline Cyprus & 2.325 .608 & 3.242 .957 & 917.349 & $39 \%$ & 14.377 .667 & 17.573 .684 & 3.196 .017 & $22 \%$ \\
\hline Corse & 2.016 .110 & 2.901 .518 & 885.408 & $44 \%$ & 6.240 .956 & 10.675 .065 & 4.434 .109 & $71 \%$ \\
\hline Crete & 2.237.139 & 5.048 .131 & 2.810 .992 & $126 \%$ & 15.324 .936 & 28.006 .885 & 12.681 .949 & $83 \%$ \\
\hline Balearic Islands & 9.416 .695 & 12.425 .741 & 3.009 .046 & $32 \%$ & 62.166 .198 & 68.376 .034 & 6.209 .836 & $10 \%$ \\
\hline NE Aegean Islands & 327.188 & 402.581 & 75.393 & $23 \%$ & 1.659 .124 & 2.007 .723 & 348.599 & $21 \%$ \\
\hline Evia & 238.463 & 307.871 & 69.408 & $29 \%$ & 1.174 .998 & 1.209 .719 & 34.721 & $3 \%$ \\
\hline Ionian Islands & 1.117 .009 & 2.315 .832 & 1.198 .823 & $107 \%$ & 7.522 .757 & 12.917 .772 & 5.395 .015 & $72 \%$ \\
\hline Dodekanisa & 1.681 .136 & 3.887 .779 & 2.206 .643 & $131 \%$ & 13.010 .561 & 24.579 .700 & 11.569 .139 & $89 \%$ \\
\hline Cyclades & 459.411 & 1.926 .589 & 1.467 .178 & $319 \%$ & 1.679 .526 & 6.206 .015 & 4.526 .489 & $270 \%$ \\
\hline Sporades & 107.015 & 154.617 & 47.602 & $44 \%$ & 616.782 & 873.707 & 256.925 & $42 \%$ \\
\hline Malta & 1.193 .033 & 2.022 .912 & 829.879 & $70 \%$ & 8.082 .229 & 9.911 .282 & 1.829 .053 & $23 \%$ \\
\hline Argosaronicos & 77.238 & 149.692 & 72.454 & $94 \%$ & 214.805 & 416.518 & 201.713 & $94 \%$ \\
\hline Tuscan Islands & 466.624 & 468.965 & 2.341 & $1 \%$ & 2.980 .209 & 2.884 .697 & -95.512 & $-3 \%$ \\
\hline
\end{tabular}

Source: Observatory on Tourism in the European Islands - OTIE

On average, the length of stay across the area was 4,7 days. Some differences should be noted beyond the individual contexts that can be highlighted according to four categories in which the islands have been divided. The average length of stay is quite similar for small islands, micro-islands, and medium islands (5 days) and coherent with the general average shown. A lower length of stay on average lower is recorded in more extensive contexts (3,7 days in the large islands). In that respect, a reflection is needed. Let us suppose the result regarding small islands is due in part to 3,2 days of Cyclades and four days of Evia, excluding which the category would have an average of 5,6 days. In that case, the large islands appear unable to restrain their guests for longer than the weekend, especially Sicily with its three days. This shows that broader contexts, which would suggest a more significant presence of tourist attractions or a more significant number of sights, things to do and places to visit, fail to become holiday destinations probably due to a lack of diversification of the supply.

Even within the same year, the flows were not evenly distributed in all island contexts. In general, tourist movements are more concentrated around May to September. Some isolated cases of seasonality extended from April to October, indicating the presence of a type of resort tourism, which makes the Mediterranean one of the favourite locations for the summer holiday.

Overall, both arrivals and nights have registered positive inflexions in the islands of the Mediterranean, in the ten years from 2007-2019, with increases which are more significant than 15.000.000 for appearances and more than 50.000.000 for presences.

Evaluating the overall result in the observed years, the scenarios have recorded an increase of $53 \%$ in arrivals and $34 \%$ in the overnight stay, highlighting a tendency towards more numerous but short travel. The best performances have been recorded by the Greek Islands, Malta, and Sardinia, which show an increase greater than 50\% in arrivals, and Greek Islands and Corse with an increase greater than $70 \%$ of overnights. 


\section{Data Analysis and results}

The first indicator analyzed is the territorial density index. It allows you to assess how many beds are available per km2. The first interesting result concerns the Maltese archipelago, which shows the highest concentrations of beds on their territory in 2019, followed by the Italian Tuscan archipelago. Lower index values are found in two Greek islands (the North-Eastern Aegean Islands and Evia) and the two large Italian islands. Another indicator to be considered is the Occupancy Rate. The numerator indicates the number of visitors' overnight stays. The denominator is the potential number of overnights stays, i. e. the total number of available beds in that year.

This index expresses the efficiency of the management in terms of the ability to maximise the occupancy of the accommodation establishment.

Malta highlights the best value of this rate in both years observed. The last indicator concerning the supply structure considers the average size of the accommodation establishments in each insular context examined. In general, the size of the accommodation establishments is relatively stable from 2007 to 2019. The most significant structures are in Malta, Corse, the Balearic Islands and Dodekanisa, with an average size higher than 150 beds. The territorial exploitation index measures the pressure on the environment from tourist and resident populations from the demand side. It relates the impact of tourist arrivals and residents to the territory's total area. Its value can be regarded as an indirect measure of stress that tourists and residents carry on the infrastructures of the region.

Table 4. Selected indicators examined.

\begin{tabular}{cc}
\hline Index & Statistical Indicator \\
\hline Territorial Density Index - TDI & $\frac{\text { Beds }}{\text { Surface }(\text { KM } 2)}$ \\
\hline Occupancy Rate - OR & $\frac{\text { Nights }}{\text { Beds } * 365}$ \\
\hline Average Size of establishments - AS & $\frac{\text { Total number of beds }}{\text { Total number of establishments }}$ \\
\hline Territorial Exploitation Index - TEI & $\frac{\text { Arrivals }+ \text { Residents }}{\text { Km } 2}$ \\
\hline
\end{tabular}

Comparative analysis of tourist industry/performances in Mediterranean islands requires a selection and evaluation of a set of indicators for all the territorial contexts considered. The table below shows, for each island, the values of the chosen indicators in the two years observed.

Table 5. Tourist indexes in the European Islands.

\begin{tabular}{|c|c|c|c|c|c|c|c|c|c|}
\hline \multirow[b]{2}{*}{ Islands } & \multirow[b]{2}{*}{ Island Group } & \multicolumn{2}{|c|}{ TDI } & \multicolumn{2}{|c|}{ OR } & \multicolumn{2}{|c|}{ AS } & \multicolumn{2}{|c|}{ TEI } \\
\hline & & 2007 & 2019 & 2007 & 2019 & 2007 & 2019 & 2007 & 2019 \\
\hline Sicily & \multirow{2}{*}{ Large } & 7,06 & 8,21 & 0,22 & 0,20 & 48,32 & 28,22 & 3,76 & 3,90 \\
\hline Sardinia & & 7,86 & 9,02 & 0,17 & 0,19 & 69,55 & 38,02 & 1,64 & 2,10 \\
\hline Cyprus & \multirow{3}{*}{ Medium } & 10,01 & 9,75 & 0,43 & 0,53 & 102,63 & 110,52 & 3,36 & 4,80 \\
\hline Corse & & 15,20 & 18,90 & 0,13 & 0,18 & 213,80 & 184,51 & 2,64 & 3,74 \\
\hline Crete & & 18,13 & 22,80 & 0,28 & 0,41 & 98,21 & 115,27 & 3,44 & 6,88 \\
\hline Balearic Islands & \multirow{6}{*}{ Small } & 87,41 & 94,15 & 0,39 & 0,40 & 171,58 & 168,73 & 21,02 & 27,40 \\
\hline North Eastern Aegean Islands & & 4,99 & 5,41 & 0,21 & 0,24 & 52,60 & 59,41 & 1,24 & 1,48 \\
\hline Evia & & 4,80 & 4,78 & 0,18 & 0,19 & 75,51 & 68,62 & 1,21 & 1,36 \\
\hline Ionian Islands & & 37,51 & 42,27 & 0,22 & 0,34 & 99,19 & 102,86 & 5,51 & 10,31 \\
\hline Dodekanisa & & 50,54 & 70,12 & 0,29 & 0,40 & 124,04 & 157,11 & 7,85 & 17,05 \\
\hline Cyclades & & 22,59 & 25,83 & 0,09 & 0,29 & 52,62 & 52,28 & 2,52 & 9,03 \\
\hline Sporades & \multirow{4}{*}{ Micro } & 25,58 & 26,36 & 0,16 & 0,22 & 66,25 & 73,29 & 2,94 & 4,12 \\
\hline Malta & & 129,21 & 152,20 & 0,54 & 0,56 & 245,96 & 197,11 & 50,74 & 79,64 \\
\hline Argosaronicos & & 27,02 & 31,19 & 0,08 & 0,14 & 44,07 & 41,12 & 4,98 & 8,01 \\
\hline Tuscan Islands & & 141,29 & 142,95 & 0,22 & 0,21 & 79,99 & 54,23 & 19,08 & 19,27 \\
\hline
\end{tabular}

Source: Observatory on Tourism in the European Islands - OTIE 
Table 5 shows the variation of 2019/2007 for each observed statistical indicator for each island cluster. Corsica, Cyprus, and the Tuscan Islands reduced the Territorial Exploitation Index and, therefore, tourist pressure on the territory. The TEI indicator shows a general increase in territorial pressure in all the islands. The most significant increase is for the Dodecanese, the Cyclades, the Ionian Islands, and Sardinia. In terms of Occupancy Rate, the Cyclades recorded the best increase in the observed period. The concentration of beds is relatively stable, except that for Dodekanisa which show a higher density and a greater average size in 2019 than in 2007.

Since the obtained values are quite different from each other, we proceed with standardising the data based on the territorial extension of the islands and the maximum value recorded for each index. This normalisation leads to a more equal comparison between the different contexts with several structural differences. They are normalised on the maximum value recorded for each islands cluster dimension. It does not express the maximum value of the indicator in absolute terms.

The islands comparative analysis considers the relationship between tourist pressure on the destination, measured by the Territorial Exploitation Index (TEI), with the three other statistical indicators concerning the structural endowment. This allow to analyse the positioning in respect the two dimension simultaneously observed. The graphs show the positioning of the islands according to the relations observed between the two statistical indicators in 2007/2019. The first graph compares the relationship and evolution between TEI and the Occupancy Rate (OR). Low TEI characterises the second quadrant's optimal positioning, where the high OR levels indicate an excellent tourism industry performance and a contained pressure on islands. Considering a dynamic view, data show a general trend to the first quadrant: an increase in efficiency, as the rate of beds occupancy increases, with a reduction in sustainability expressed by the rise in the pressure on the island. This is especially true in the case of Sardinia and the Dodecanese, which pass from the second to the first quadrant during the observed period. Although it remains in the 1st quadrant, Cyprus significantly reduced its tourist pressure while maintaining production efficiency. In 2019, the Cyclades Islands improved both parameters and moved from the third to the second quadrant.

Precisely, small and micro islands lie in the second and third quadrants both in 2007 and 2019, at least moving within them. For example, the Tuscan islands and the Ionian archipelago improve their results by reducing the TEI value. Among these islands, the only exception is the Dodekanisa, which moves from the second quadrant (the best position) to the first one, getting worse in sustainability. The Balearic archipelago and Malta maintain Sicily's position, the largest Mediterranean island.

Large and medium islands are between the first and the last quadrant, highlighting less attention to socio-environmental issues. Cyprus and Corse reduced the TEI from 2007 to 2019, while Sardinia moved from the best quadrant to the first one, improving the efficiency at the expense of sustainability.

The second analysis concerns the relationship between the TEI and the structural characteristics of the tourism supply, described by the average size indicator (AS) of the accommodation facilities. In this case, the desirable positions are indifferently the II and III quadrants, connected to a low socio-environmental impact. Dodecanese and Sardinia worsen the performance related to environmental pressure and move from the second to the first quadrant. In parallel, in 2019, Corse Island showed more significant attention to sustainability positioning almost at the border between the I and the II quadrant. Besides, Cyprus improved its performances by reducing the socio-environmental impact, as revealed by moving from the top side of the last towards the lower part of the first quadrant. 


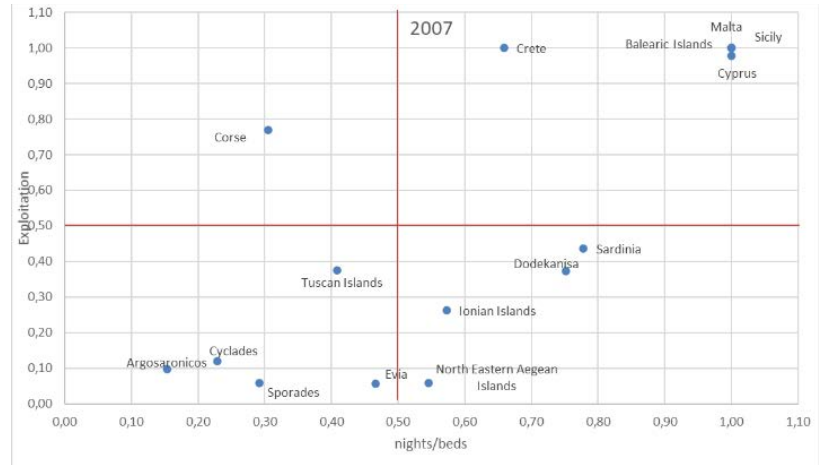

(a)

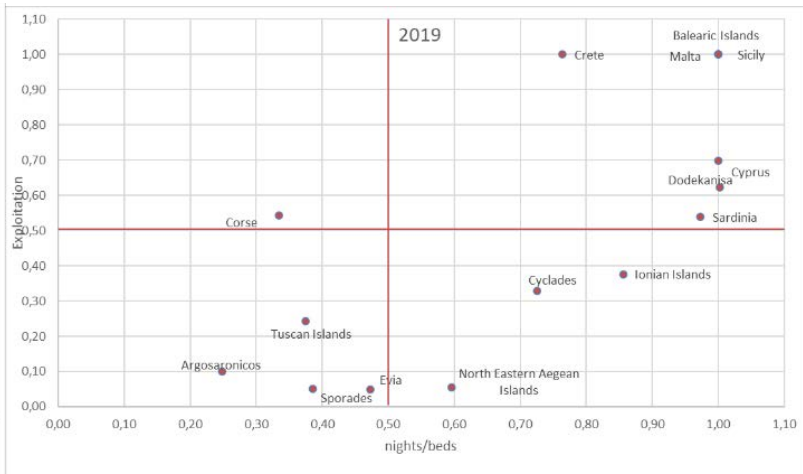

(b)

Figure 1. Territorial Exploitation Index and Occupancy Rate in year 2007 (a) and in year 2019 (b); Source: Observatory on Tourism in the European Islands - OTIE.

In general, as in the previous example, the large and medium islands have the worst positioning in the first quadrant, with a high average size of the accommodation facilities and an equally high value of the TEI. Also, Sardinia, which in 2007 was in the II quadrant, in 2019 moves in the first one. Small and micro insular contexts lie in the second and third quadrants both in 2007 and 2019, except for the Spanish archipelago and Malta, which have the exact position of the big islands.

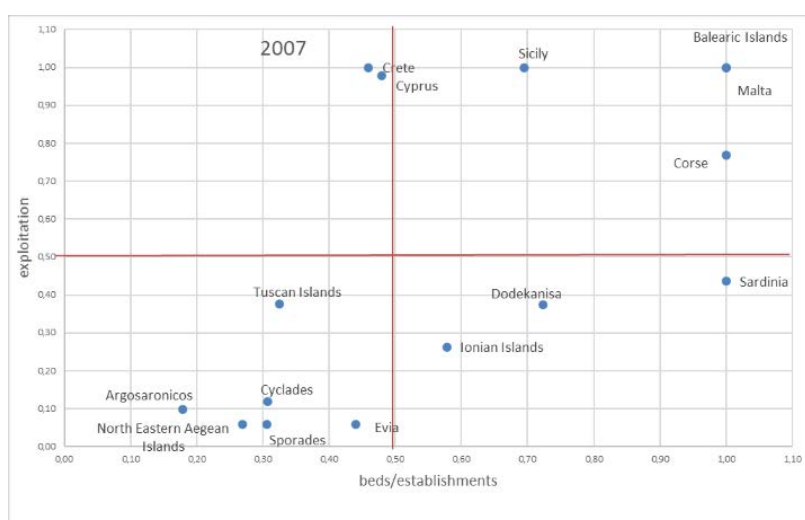

(a)

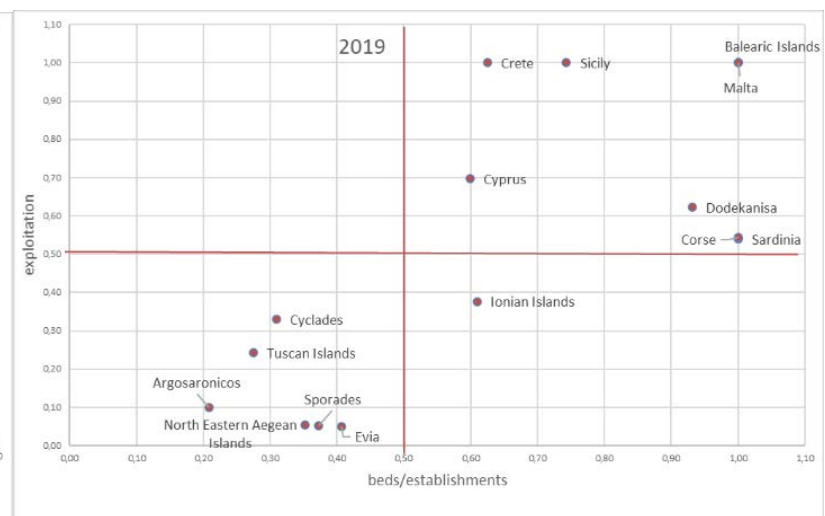

(b)

Figure 2. Territorial Exploitation Index and the average size of accommodation establishments in year 2007 (a) and in year 2019 (b); Source: Observatory on Tourism in the European Islands - OTIE.

Graph 3 compares TEI with the Territorial Density Index (TDI), which concerns the territorial concentration of tourist supply in terms of beds. The best positioning is the III quadrant, characterized by low beds on the territory and low-pressure levels.

The small and micro islands have the lowest values of the TEI and are in the II and II quadrants, except for Malta and Balearic, which follow the large islands. Dodekanisa, among the small contexts, and Sardinia, among the large ones, move from the II to the I quadrant and both worsen their position in terms of density of beds and TEI. Cyprus improves its performance moving from the top side of the first quadrant to the lower part of the last one, with a lower TEI and density of beds for square kilometer. Corse stays within the first quadrant reducing socio-environmental impact, moving towards the lowest part of the area. Six island contexts take up the win-to-win position in the two observed years (quadrant III). These are small and micro contexts, highlighting once again greater environmental attention than larger ones. 


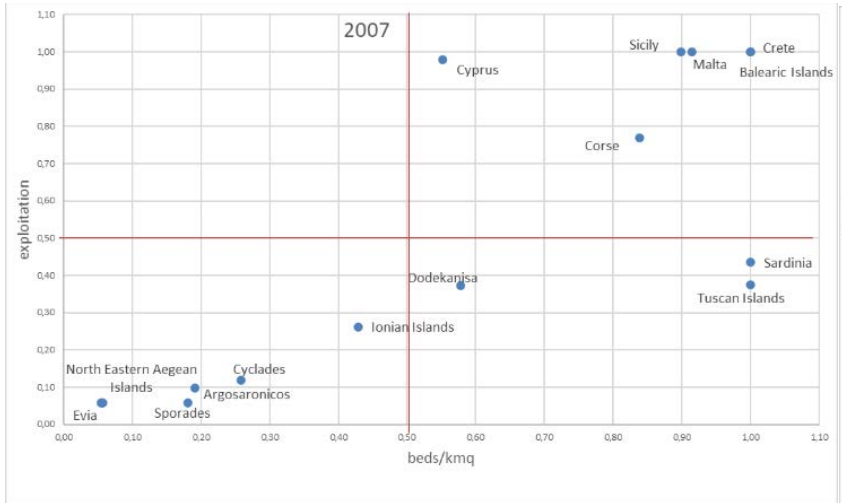

(a)

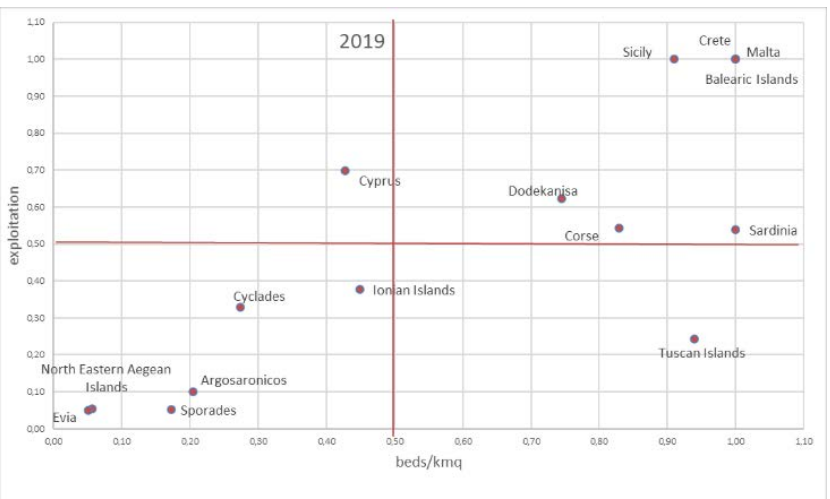

(b)

Figure 3. Territorial Exploitation Index and the average size of accommodation establishments in year 2007 (a) and in year 2019 (b); Source: Observatory on Tourism in the European Islands - OTIE.

\section{Discussions. Policy implication for Mediterranean islands}

Fifteen insular contexts belonging to six different countries, Cyprus, Greece, Italy, Malta, France, and Spain, were compared to highlight general findings and specific features.

Insular contexts are different in geo-demographic and institutional dimensions and terms of tourism development.

The various combination of territorial extension, population, and tourism industry characteristics leads to different socio-environmental impacts and levels of efficiency in managing the tourism industry in two different periods of time.

The distribution of the tourist supply is not uniform in all the islands. The Spanish archipelago is the first in terms of beds, counting more beds than Sardinia and Sicily, although characterised by a territorial extension equal to one-fifth of Sicily, which is the largest Mediterranean island. Here we find the highest portion of tourist accommodation structures (30,6\%), followed by Sardinia with $23,4 \%$.

Considering the size of the structures, the highest number of beds is in hotel accommodations (1.355.348, in 2019). With more than 100 beds, the largest hotels are in the Balearic Islands, the Maltese archipelago, the Dodecanese Islands, Sardinia, Crete, Cyprus, and Ionian islands.

The other accommodation facilities are smaller than the previous one, except for $\mathrm{Cy}$ prus and Corse, equipped with a small number of large structures with an average size of 494 beds and 308 beds for establishment. This figure is not surprising given that the main kind of other facilities in these contexts is camping. In 2019, both arrivals and overnights increased in the islands of the Mediterranean basin ( $+53 \%$ and $+34 \%$, respectively). Remarkably, $52 \%$ of arrivals are due to the Balearic Islands, Sicily, Crete, and $56 \%$ of overnights can be attributed to the Balearic Islands, Crete, and the Dodecanese. The Spanish archipelago, in itself, represents almost $30 \%$ of arrivals to Mediterranean islands and $32 \%$ of the total overnight stays corresponding to more than 68 million nights. Considering the variation in the observed period, the best performances have been recorded by the Greek Islands, Malta, and Sardinia, which show an increase greater than $50 \%$ in arrivals, and Greek Islands and Corse with an increase greater than $70 \%$ of overnights.

Malta shows the highest TEI and TDI values in sustainability and socio-environmental impact.

By focusing on the deviations recorded by each index during the period 2007-2019, the best and worst cases can be highlighted. Corsica, Cyprus, and the Tuscan Islands show to have reduced the Territorial Exploitation Index and, therefore, tourist pressure on the territory. The islands that experienced the most significant increase in this indicator are the Dodecanese, the Cyclades, the Ionian Islands, and Sardinia. In terms of Occupancy Rate, the Cyclades recorded the best increase in the observed period $(+0,5)$. The 
concentration of beds is relatively stable, except that for Dodekanisa showing a higher density $(+0,17)$ and a greater average size $(+0,21)$ in 2019 than in 2007.

Comparing the TEI index with the other three indicators selected, greater attention to sustainable aspects in the small contexts can be observed. Large islands always appear in the quadrant corresponding to the higher socio-environmental pressure.

In general, the Cyclades, the Ionian islands and the North-Eastern Aegean Islands are always in the win-to-win quadrant. On the other hand, large and medium insular contexts show always low sustainability positions. Balearic and Malta, among the small and micro contexts, show the same positioning. Sardinia began with a sustainable approach in 2007, moving towards the I quadrant in 2019, getting worse in terms of socio-environmental impact.

\section{Conclusions. Islands tourism policy implications}

Islands are considered fragile territories due to the physical and economic limited resources and an unstable environmental balance. Sustainability aspects are always regarded as central for those territories, and at the same time, the need to support local economies through tourism is considered essential. The paper compared Mediterranean islands performances by using statistical indicators considering island clusters. The analysis shows that islands are characterized by a model of tourist development that has encouraged the construction of large hotels with a high average number of beds per establishment, thus creating sizeable and prominent tourist destinations.

The need to increase the number of tourism establishments, number of beds, and the need to rise in efficiency measured by beds occupancy resulted in a rise in islands pressure between 2007/2019. Analysis results are more evident for large and medium Mediterranean islands and in the case of large archipelagos. Due to this comprehensive tourism policy, the pressure on the islands is increasingly attracting more visitors to islands with an increase in tourists and overnights. Conversely, small and micro islands kept a contained pressure in 2007/2019 by choosing a small establishment dimension.

The analysis could further consider other external factors that influenced the increase of tourist supply: territorial dimensions, ability to attract investment, size of flows, and different time stages of these destinations' life cycles.

From the results obtained island dimensions show a natural limitation in tourism investments. Large and medium islands and archipelago offer a development model based on the tourism industry model, increasing the industry following the increase in tourism demand before the covid-19 pandemic. The rise in island pressure was not considered a limitation, and the expansion of the market supported the economic growth in the industry and local economy. Small and micro islands followed a more balanced model, by following the demand increase which adopted policies to keep a moderate level of pressure and islands sustainability.

The analysis represents a starting point for further studies and insights. Mediterranean islands need to address strategic development policy to ensure economic efficiency and at the same time respecting local environment and culture. In this context, new technologies as well as European strategies could support the management to take action on specific issues, like urban and environmental planning, mobility, smart cities, waste and water management, energy consumption, promotion of local culture, tourists' flows management.

Furthermore, advances in ICT help improve destination management and promotion at the same time arising visitors' awareness towards a tourism which respect local people and resources [49].

Author Contributions: The authors equally contribute to each section of the paper. They have read and agreed to the published version of the manuscript.

Funding: This research received no external funding. 


\begin{abstract}
Institutional Review Board Statement: Not applicable
Informed Consent Statement: Not applicable.
\end{abstract}

Data Availability Statement: data supporting reported results can be found at Eurostat Database https://ec.europa.eu/eurostat/data/database/

Conflicts of Interest: The authors declare no conflict of interest.

\title{
References
}

1. Brida, J. G.; Rodríguez Brindis, M.; Mejía-Alzate, M. L. La contribución del turismo al crecimiento económico de la ciudad de Medellín - Colombia. Revista de Economía del Rosario 2021, 24(1), 1-23. https://doi.org/10.12804/revistas.urosario.edu.co/economia/a.8926

2. Webster, C.; Ivanov, S. Transforming competitiveness into economic benefits: Does tourism stimulate economic growth in more competitive destinations? Tourism Management 2014, 40, 137-140.

3. Dogru, T.; Bulut, U. Is tourism an engine for economic recovery? Theory and empirical evidence. Tourism Management 2018, 67, 425-434. https://doi.org/10.1016/j.tourman.2017.06.014

4. Seghir, G. M.; Mostéfa, B.; Abbes, S. M.; Zakarya, G. Y. Tourism spending-economic growth causality in 49 countries: A dynamic panel data approach. Procedia Economics and Finance 2015, 23(1613-1623). https://doi.org/10.1016/S2212-5671(15)00402-5

5. Du, D.; Lew, A. A.; Ng, P. T. Tourism and economic growth. Journal of Travel Research 2016, 55(4), 454-464. https://journals.sagepub.com/doi/abs/10.1177/0047287514563167

6. Mitra, S. K. Is the tourism-led growth hypothesis still valid? International Journal of Tourism Research 2019, 21(5), 615-624. https://doi.org/10.1002/jtr.2285

7. Lin, V. S.; Yang, Y.; Li, G. Where can tourism-led growth and economy-driven tourism growth occur? Journal of Travel Research 2019, 58(5), 760-773. https://doi.org/10.1177/0047287518773919

8. Candias, K.; Leticia Rojas, M.; London, S. Turismo y Crecimiento en América Latina y Caribe: ¿ causa o consecuencia? Economia Coyuntural 2020, 5(3), 99-135.

9. Dritsakis, N. Tourism development and economic growth in seven Mediterranean countries: A panel data approach. Tourism Economics 2012, 18(4), 801-816.

10. Dineri, E. Are number of tourist arrivals the driving force of economic growth in Mediterranean countries? Augmented mean group estimator. Kahramanmaraş Sütçü İmam Üniversitesi Sosyal Bilimler Dergisi 2020, 17(2), 987-1006. DOI: 10.33437/ksusbd.739107

11. Croes, R.; Vanegas Sr, M. Cointegration and causality between tourism and poverty reduction. Journal of travel research 2008, 47(1), 94-103.

12. Briguglio, L. Small Island developing states and their economic vulnerabilities. World Development 1995, 23, 1615-1632.

13. Gössling, S. Market integration and ecosystem degradation: is sustainable tourism development in rural communities a contradiction in terms? Environment, Development and Sustainability 2003, 5(3), 383-400.

14. Ruggieri, G., Calò, P., \& Orthodoxou, K. Overtourism and undertourism: ICT in island development policy. In Brinklow L, Liyun L., Qinhong C., \& Randall J. (a cura di), Annual Report on Global Islands. Charlottetown: Island Studies Press at the University of Prince Edward Island 2020, 85 - 108. https://projects.upei.ca/unescochair/annual-report-on-global-islands-2019/

15. McKinsey \& Company and World Travel \& Tourism Council. Coping with success: Managing overcrowding in tourism destination. New York: McKinsey \& Company and World Travel \& Tourism Council 2017

16. Peeters, P.M., Gössling, S., Klijs, J., Milano, C., Novelli, M., Dijkmans, C.H.S., Eijgelaar, E., Hartman, S., Heslinga,J., Isaac, R., Mitas, O., Moretti, S, Nawijn, J., Papp, P., \& Postma, A. Research for TRAN Committee-Overtourism: Impact and possible policy 108 O V E R TO U R I S M A N D U N D E R TO U R I S M responses. Brussels: European Parliament, Directorate General for Internal Policies, Policy Department B: Structural and Cohesion Policies, Transport and Tourism. 2018

17. Briguglio, L., \& Avellino, M. Has overtourism reached the Maltese Islands? Malta: University of Malta Islands and Small States Institute 2019

18. Craigwell, R., \& Maurin, A. A sectoral analysis of Barbados' GDP business cycle. Journal of Eastern Caribbean Studies, 2007, 32(1), 21-52.

19. Griffith, W.H. A tale of four CARICOM countries. Journal of Economic Issues, 2002, 36(1), 79-106

20. Chen, R.J. Islands in Europe: Development of an island tourism multi--dimensional model (ITMDM). Sustainable Development, 2006, 14(2), 104-114.

21. Sharpley, R. Tourism, modernisation and development on the island of Cyprus: Challenges and policy responses. Journal of Sustainable Tourism, 2003, 11(2-3), 246-265.

22. Obrador, P.; Crang, M.; Travlou, P. Taking Mediterranean tourists seriously. Ashgate 2009, 1-20.

23. Hall, C. M. Changing paradigms and global change: From sustainable to steady-state tourism. Tourism Recreation Research 2010, 35(2), 131-143.

24. Sharpley, R. The myth of sustainable tourism. CSD Center for Sustainable Development, 2010. 
25. Hall, C. M. Framing behavioural approaches to understanding and governing sustainable tourism consumption: Beyond neoliberalism, "nudging" and "green growth"? Journal of sustainable tourism 2013, 21(7), 1091-1109.

26. Making Tourism More Sustainable - A Guide for Policy Makers, UNEP and UNWTO, 2005, p.11-12

27. Cole, S. Synergy and congestion in the tourist destination life cycle. Tourism Management 2012, 33(5), 1128-1140.

28. Kim, K.; Uysal, M.; Sirgy, M. J. How does tourism in a community impact the quality of life of community residents? Tourism Management 2013, 36, 527-540.

29. Garau Taberner, J.; Manera, C. The recent evolution and impact of tourism in the Mediterranean: the case of island regions, 1990-2002, Social Science Research Network Electronic Paper Collection 2006: http://ssrn.com/abstract=927743

30. Godenau, D.; Martín, R. H. Insularidad: ¿ Un concepto de relevancia analítica? Revista de estudios regionales 1996, 45, 177-194.

31. Deidda, M. Insularity and economic development: A survey. International Review of Economics 2016, 63(2), 107-128.

32. Conkling, Philip. On islanders and islands. Geographical Review 2007, Vol. 97, No. 2. pp. 191-201. DOI: 10.2307/30034161 //www.jstor.org/stable/30034161

33. Selwyn, P. Smallness and islandness. World Development 1980, Volume 8, Issue 12. https://doi.org/10.1016/0305-750X(80)90086$\underline{8}$

34. Armstrong, H. W.; Read, R. Insularity, remoteness, mountains and archipelagos: a combination of challenges facing small states. In international conference on the political economy of small islands, Victoria University of Wellington (2004, April).

35. Armstrong, H.; Ballas, D.; Staines, A. A comparative analysis of the economic performance of Greek and British small islands. In 36th Regional Science Association International (British and Irish Section) conference (2006, August).

36. Cerina, F.; Cocco, L.; Mannaro, K.; Marchesi, M.; Pigliaru, F. Insularity and the development of a local railway network. Economia Politica 2020, 37(2), 683-702.

37. Cocco, L; Deidda, M.; Marchesi, M.; Pigliaru, F. Insularity and economies of density: analysing the efficiency of a logistic network using an econometric simulation-based approach. Regional Studies 2019, Vol. 53, n. 6, pp. 900-911 https://doi.org/10.1080/00343404.2018.1490500

38. Spilanis, I.; Kizos, T.; Vaitis, M.; Koukourouvli, N. Measuring the economic, social and environmental performance of European island regions: Emerging issues for European and regional policy. European Planning Studies 2013, 21, 1998-2019. doi:10.1080/09654313.2012.722970

39. Espon. The Development of the Islands, European Islands and Cohesion Policy (EUROISLANDS). Interim Report 2013.

40. Espon. Transport Accessibility at Regional/Local Scale and Patterns in Europe. TRACC Main Report 2015, Volume 1b

41. Briguglio, L; Cordina, G; Farrugia, N.; Vella, S. Economic Vulnerability and Resilience: Concepts and Measurements. Oxford Development Studies 2009, 37:3, 229-247, DOI: 10.1080/13600810903089893

42. Becker C. The Small Island States in the Pacific: The Tyranny of Distance. Technical report, International Monetary Fund 2012.

43. Croes, R. R. A paradigm shift to a new strategy for small island economies: Embracing demand-side economics for value enhancement and long-term economic stability. Tourism Management 2006, 27(3), 453-465.

44. Ruggieri, G., \& Vazquez, F.J.C. Tourism development in UNESCO natural heritage sites-The case of Sicilian volcanic sites: Mount Etna and Aeolian Islands. Chinese Business Review, 2017, 16(11), 544-554.

45. Boadas, A. R. Islas e insularidad geográfica. Terra 2011, 27(41), 147-154.

46. EUROSTAT, Portrait of Islands, European Commission, 1994.

47. Ruggieri G., Calò P. Italy's Island Systems: Competitiveness in the Mediterranean Context. In Grasso F., \& Sergi B. (a cura di), Tourism in the Mediterranean Sea: an Italian perspective (pp. 309-319). Bingley: Emerald Publishing Limited 2021. http://dx.doi.org/10.1108/978-1-80043-900-920211021

48. Cannonier, C.; Burke, M. G. The economic growth impact of tourism in Small Island Developing States-evidence from the Caribbean. Tourism Economics 2019, 25(1), 85-108.

49. Ruggieri, G., \& Calò, P. ICT and tourism impacts in islands. Ecocycles, 2018, 4(2), 4-11. DOI: 10.19040/ecocycles.v4i2.102 